\title{
Homolateral ataxia and crural paresis: a crossed cerebral-cerebellar diaschisis
}

\author{
M Giroud, E Creisson, H Fayolle, P Gras, P Vion, F Brunotte, R Dumas
}

\begin{abstract}
A patient developed weakness of the right leg and homolateral ataxia of the arm, caused by a subcortical infarct in the area supplied by the anterior cerebral artery in the left paracentral region, demonstrated by CT and MRI. Cerebral blood flow studied by technetiumlabelled hexamethyl-propylene-amine oxime using single photon emission computed tomography showed decreased blood flow in the left lateral frontal cortex and in the right cerebellar hemisphere ("crossed cerebral-cerebellar diaschisis"). The homolateral ataxia of the arm may be caused by decreased function of the right cerebellar hemisphere, because of a lesion of the corticopontine-cerebellar tracts, whereas crural hemiparesis is caused by a lesion of the upper part of the corona radiata.
\end{abstract}

$(\Im$ Neurol Neurosurg Psychiatry 1994;57:221-222)

Homolateral ataxia and crural paresis described by Fisher and Cole ${ }^{1}$ in 1965, is often considered to be a variant of the lacunar syndrome of ataxic hemiparesis, but most recent clinical studies of lacunar syndromes have not included it in the ataxic hemiparesis group. ${ }^{2}$ It is thought that the syndrome may be a manifestation of anterior cerebral artery (ACA) territory infarction. ${ }^{3}$ Our patient accords with Bogousslavsky's observations ${ }^{3}$ and suggests that this syndrome is caused by crossed cerebral-cerebellar diaschisis.

Service de Neurologie, Hôpital Général,

Dijon, France

$M$ Giroud

E Creisson

H Fayolle

$P$ Vion

P Gras

R Dumas

Service de Médecine Nucléaire, Centre GF Leclerc, Dijon, France F Brunotte

Correspondence to: Dr M Giroud, Service de Neurologie, Hôpital Général, 3 Rue du Faubourg Raines, 21000 Dijon, France.

Received 18 February 1993 and in revised form 28 May 1993.

Accepted 8 June 1993

\section{Case report}

A 72-year-old man with a history of smoking, slight alcoholism, and arterial hypertension, suddenly developed weakness of the right leg and incoordination of the right arm. On examination six hours later, he was alert and well oriented in time and place. Speech was normal. There were no abnormalities of cranial nerves. In his right leg the paresis was most marked proximally, with normal tone, but with increased tendon reflexes, and plantar responses were extensor. Light touch, temperature, pain, position, and vibration sense were normal. There was no paresis in his right arm, but there was a marked ataxia demonstrated by an abnormal finger-to-nose test. Alternate movements were slow and saccadic on the right arm with large oscillations. Light touch, temperature, pain, position, and vibration sense were normal. Tendon reflexes were normal. The gait was ataxic. Neuropsychological examination was normal. There was no dysarthria, no gaze disturbance, no incontinence, or grasp reflex. Blood pressure was $160 / 90 \mathrm{mmHg}$. CT seven days after onset showed an area of decreased lucency (fig 1) with a slight contrast enhancement centred in the white matter of the left paracentral area. MRI one month later showed focal atrophy of the left anterior paracentral area belonging to the left ACA territory, with no lesion in the cerebellum (fig 2). Extra- and intracranial Doppler ultrasound examination was normal. Electrocardiogram, transthoracic, and transoesophageal echocardiography were normal. A battery of blood and urine tests was normal. Thirteen days after onset, cerebral blood flow was performed with technetium $99 \mathrm{~m}$-labelled hexamethylpropylene-amine oxime (HMPAO) and single photon emission computed tomographic (SPECT) imaging with a conventional single-

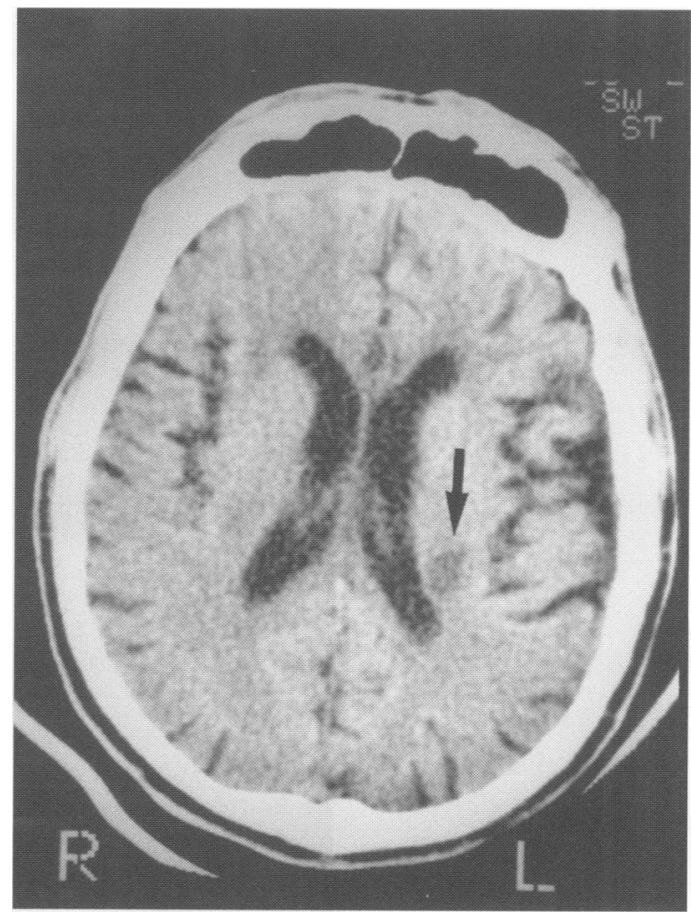

Figure 1 Decreased lucency in white matter of the left paracentral area on CT (arrow). 
Figure 2 MRI one month later: atrophy of the left anterior cerebral artery territory (arrow).

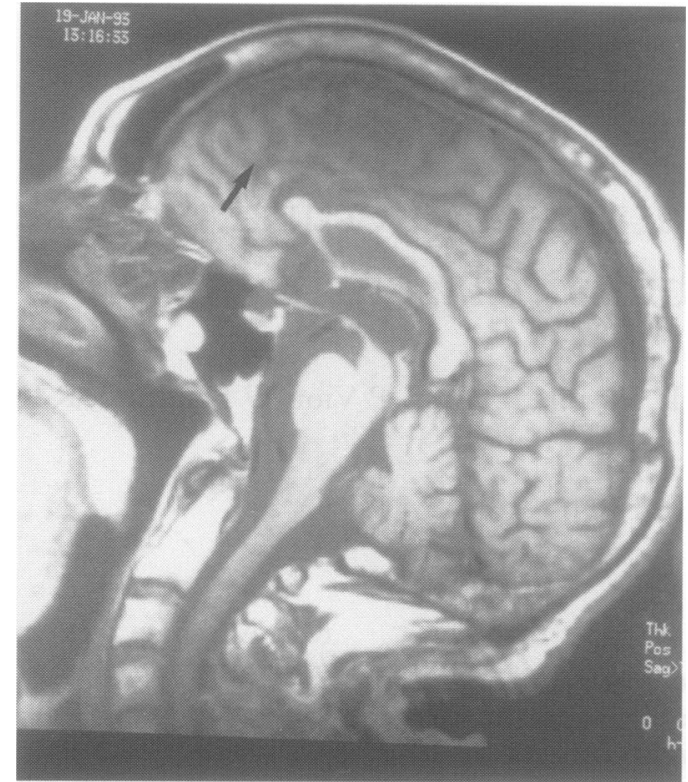

head rotating camera system (the Orbiter camera system of Siemens). Final SPECT slices were oriented parallel to the skull base to correspond to the CT scan and had a slice thickness of approximately $12 \mathrm{~mm}$. Regional blood flow was compared qualitatively from one hemisphere to one another with a multicoloured scale. We observed a decrease in blood flow in the left frontal lobe and in the right cerebellar area (fig 3). The ratio of the difference between the right and left cerebellar blood flow (mean of two values) was $21 \%$.

Fifteen days later, a slight, right-sided foot paresis with ataxic gait persisted, but the right hand was no longer ataxic.

\section{Discussion}

This case is similar to the five cases reported by Bogousslavsky et $a l,{ }^{3}$ in whom homolateral arm ataxia and crural paresis were associated with an infarction of the ACA territory. In three other patients ${ }^{4-5}$ with such symptoms,

Figure 3 Decreased blood flow in the right cerebellar lobe (arrow) on SPECT.

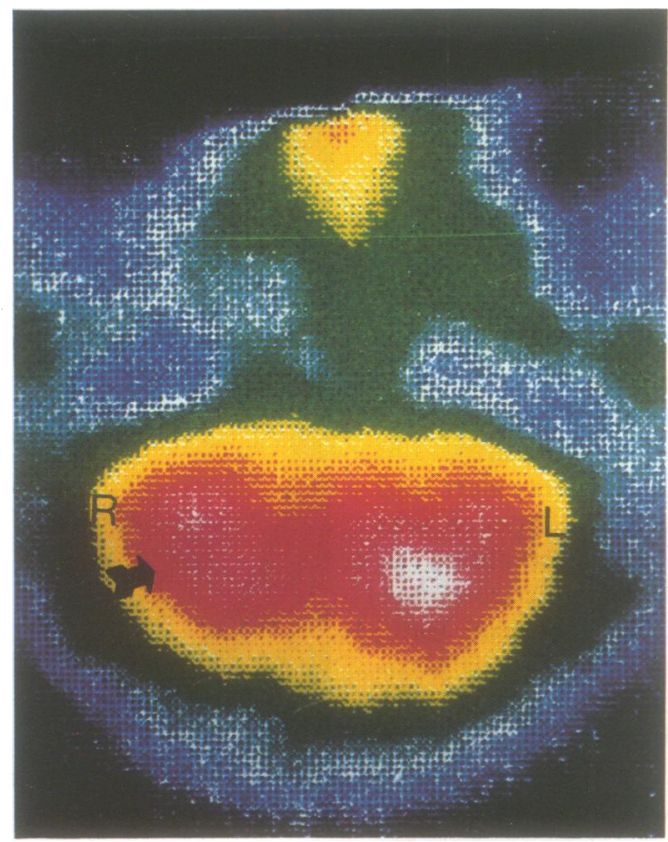

CT revealed an infarct involving the upper part of the corona radiata adjacent to the lateral ventricle, an area that corresponds to the subcortical part of the ACA territory where the lesion was found in the cases reported by Bogousslavsky et al. ${ }^{3}$

It is known that paracentral tumours may give cerebellar signs. ${ }^{6-8}$ Cerebellar signs from paracentral lesions have been explained by the involvement of the paracentral tract of the frontopontine fibre tracts. ${ }^{6-8}$ Thus, a subcortical infarction in the ACA territory may involve both the corticopontine fibres close to their origin, giving cerebellar signs in the arm by 'deafferentiation', and the upper part of the corona radiata below the paracentral cortex resulting in crural hemiparesis. There is no anatomical evidence for this hypothesis, but our clinical case suggests that the two cortical outputs for arm motor function, to cerebellum and to spinal cord, are not colocalized. It is well known that cerebral infarcts are often associated with contralateral cerebellar hypoperfusion. Baron et $a l,{ }^{9}$ first described this phenomenon and called it "crossed cerebellar diaschisis". This diaschisis probably reflects the interruption of corticopontocerebellar pathways.

Crossed cerebellar diaschisis is usually associated with hemiparesis. In such cases the abnormality of movements which might result from abolished cerebellar function cannot be revealed. In our case, however, the infarct appeared to spare the cortical hand area and its output tracts to the spinal cord. Thus the cerebellar deafferentiation (diaschisis) could be disclosed. Our conclusions accord with those of Bogousslavski $e t a l^{3}$, but our case is the first in which SPECT imaging showed crossed deafferentiation, an observation strongly supporting the notion that it is indeed possible to elicit cerebellar symptoms by disrupting the corticopontine pathway and thus interrupting the cortico-cerebellarthalamic-cortical loop. ${ }^{10}$

1 Fisher CM, Cole M. Homolateral ataxia and crural paresis: a vascular syndrome. $\mathcal{F}$ Neurol Neurosurg Psychiatry sis: a vascular

2 Orgogozzo JM, Bogousslavsky J. Lacunar syndromes. In: Vinken PJ, Bruyn GW, Klawans HL, eds. Handbook of clinical neurology, Vol. 54, Vascular diseases, (Toole JF, ed.) $1989 ; 235-69$

3 Bogousslavsky J, Martin R, Moulin T. Homolateral ataxia and crural paresis: a syndrome of anterior cerebral artery territory infarction. F Neurol Neurosurg Psychiatry 1992;55:1146-9.

4 Rosa A, Mizon JP, Betermiez P. Hémiparésie crurale avec ataxie homolatérale. A propos d'un cas avec étude tomodensimétrique. Rev Oto Neuro Ophtalmol 1983; 55:283-8.

5 De Renzi E, Nichelle P, Christ G. Hemiataxia and crural hemiparesis following capsular infarct. $\mathcal{F}$ Neurol Neurosurg Psychiatry 1983;46:561-3.

6 Nicolesco J, Cretu V, Demetresco L. Syndrome de l'artère cérébrale antérieure. Monoplégie crurale droite avec symptomatologie cerebelleuse prépondérante. Bull Soc Méd Hốp Bucarest 1920;10:247-50.

7 Alajouanine T, Lemaire A. Tumeur de la région paracentrale postérieure avec symptômes pseudo-cérébelleux. trale posterieure avec sym
Rev Neurol $1925 ; 1: 71-5$.

8 Mizon JP, Rosa A. Hémiparésie à prédominance crurale et ataxie ipsilatérale par méningiome de la faux du cerveau. Rev Neurol 1986;142:68-9.

9 Baron JC, Bousser MG, Comar D, et al. "Crossed cerebellar diaschisis" in human supratentorial infarction. Ann Neurol 1980;8:128 (abstract).

10 Fulham MJ, Brooks RA, Hallett M, Di Chiro G Cerebellar diaschisis revisited: pontine hypometabolism and dentate sparing. Neurology 1992;42:2267-73. 